\title{
Creating a Sense of 'CLOSURE': Providing Confidence Intervals on some Recent Estimates of Indigenous Populations
}

\author{
Boyd H. Hunter \\ Mardi H. Dungey \\ Centre for Aboriginal Economics \\ and Policy Research \\ Australian National University \\ Canberra ACT 2000, Australia
}

\begin{abstract}
The error of closure is the population growth that cannot be accounted for by either natural increase or quantifiable non-demographic factors, and is an issue that is particularly pronounced for indigenous peoples. This paper estimates Australia's indigenous population using the dual system estimation method, and compares these to those produced using the standard undercount method. The main conclusion is that dual system estimates of the indigenous population appear to be reasonably accurate at the national level, which provide an appreciation of the reliability of existing estimates. Notwithstanding, policy makers need to take into account that population statistics are merely estimates.
\end{abstract}

Key Words: Confidence intervals, indigenous population, post-censal estimates, and post-enumeration surveys 
Boyd H. Hunter and Mardi H. Dungey

\section{Résumé}

On appelle « erreur en fin de période » la croissance démographique qui ne peut être expliquée ni par la croissance naturelle ni par des facteurs quantifiables non démographiques; ceci est une question qui s'impose plus particulièrement auprès des peuples indigènes. Cet article présente une estimation de la population indigène de l'Australie suivant la méthode de système dual et compare ces résultats avec ceux obtenus avec la méthode plus traditionnelle de sous-dénombrement. La conclusion principale est que les estimations de méthode de système dual des populations indigènes semblent être raisonnablement justes au niveau national et démontrent que l'on peut apprécier la fidélité des estimations existantes. Cependant, il est bon de rappeler aux responsables que les statistiques de population ne sont que des estimations.

Mots-clés: Les intervalles de confiance, les populations indigènes, les estimations d'après recensement, les enquêtes post-censitaires.

\section{Introduction}

One of the most contentious issues in regard to the demography of indigenous Australians is the increasing extent to which people are likely to identify in the census and other official statistical collections as indigenous (Gray 1997a; 1997b; Ross 1999; Taylor 1997a; 1997b). This phenomenon is not confined to Australia and there is a significant international literature addressing the problem (Sandefur, Rindfuss \& Cohen 1996; Snipp 1997). The term used to describe the extent to which indigenous population growth cannot be explained by either biological factors or spatial mobility is the 'error of closure' (Passel 1996; Ross 1999; Taylor 1997a).

In the context of indigenous populations, the error of closure methodology measures the difference between the expected population count and the actual population count, assuming that there is zero net immigration and that the only source of growth is natural increase. The methodology has been extended to include quantifiable non-demographic components such as changes in editing procedures (Ross 1999) and incomplete counting of the population (Guimond 1999). That is, the error of closure is the population growth that cannot be accounted for by either natural increase or quantifiable non-demographic factors. There are several possible sources of error in the error of closure calculation, for instance poor coverage of births or deaths, and differential undercount rates at each census. In addition, there are two factors that are normally cited as constituting the non-demographic increases. These are changes in census methodology (Gray 1997a), and changes in self-identification as 'indigenous' on the census form (Passel 1976; Ross 1999). 
The term 'error of closure' is somewhat misleading. Given that it incorporates all unquantifiable components of change in a population count, it is unlikely to ever be 'closed'. Unless variables were measured with absolute precision, and the underlying statistical model could perfectly predict the population count, it would be surprising if the error was ever equal to zero (i.e. 'closed'). Indeed, it would probably be an error to seek closure in the 'error of closure' because of residual randomness not accounted for in the model.

While most studies have concentrated on point estimates of the indigenous population in order to shed light on the potential for future increases in identification, this study seeks to highlight the role of variability of the estimates in such a process by calculating standard errors.

The Australian debate over increasing indigenous identification is at times emotive, especially given the tendency to conflate the numbers of people identifying as indigenous with the definition of that identity (Gardiner \& Bourke 2000; Gray 1997a). This paper does not seek to engage in such debates; rather it seeks to place bounds on the potential indigenous population using the Dual System Estimator (DSE) method. In the context of human populations, the technique was pioneered more than 50 years ago by Sekar and Deming (1949).

After a brief introduction to the trends in the error of closure in estimates of the indigenous population, the remainder of this paper reviews the Sekar-Deming method for estimating populations from survey data, and briefly reviews the literature on the strengths and weaknesses of calculating human populations using the method. Once Australia's indigenous population has been estimated using this method, confidence intervals are compared to those produced by the Australian Bureau of Statistics (ABS) using the undercount method. In the end, the most accurate method depends on the variance in the error in each collection (Wolter 1987). The conclusion develops the policy consequences and puts forward suggestions for future research.

\section{Revisiting the 'Error of Closure'}

The error of closure is the remainder after measurable demographic and administrative factors are taken into account. The starting point is what demographers sometimes refer to as the 'balancing equation' (Shyrock, Siegel \& Associates 1976: 4):

$$
\mathrm{P}_{\mathrm{t}}=\mathrm{P}_{0}+\mathrm{B}_{\mathrm{t}}-\mathrm{D}_{\mathrm{t}}+\mathrm{NM}_{\mathrm{t}}+\mathrm{CP}_{\mathrm{t}}+\mathrm{E}_{\mathrm{t}}
$$

Where $P_{t}$ is population at time $t ; P_{0}$ is the initial population estimate, $B_{t}, D_{t}$ and $\mathrm{NM}_{\mathrm{t}}$ are the births, deaths and net migration since the initial period, and $\mathrm{CP}_{t}$ is the population changes resulting from census procedures. The residual in this equation is denoted $E_{t}$, which forms the basis of the error of closure. In the case where $P_{t}$ refers to the indigenous or non-indigenous 
population only, $E_{t}$ includes the effect of the changing propensity to identify as indigenous.

The term 'balancing equation' is rather misleading because it carries the connotation of an accounting framework. However, the estimates are only balanced by adding an error term. Furthermore, since all of the terms on the right-hand side are estimates, and hence are measured with error, all these errors are reflected in the residual term, $E_{t}$. Hence the "error of closure' is an amalgam of errors.

Table 1 presents the indigenous census counts collected since national Australian statistics were first provided in 1901. The first thing to note is the variability of the population growth rate (column 4). Taylor (2002a) claims that these counts partially reflect highly variable methodology and the intent of the governments of the day. Note the annual growth rate of the indigenous population was relatively low until 1971. In a period of significant growth for the rest of the population, it is particularly noteworthy that the indigenous population often appeared to have negative growth rates. It is probably not a coincidence that 1971 was the first census year after the 1967 referendum that granted the Commonwealth the ability to make laws and systematically collect data with respect to all indigenous Australians. Arguably, non-indigenous Australians displayed considerable public goodwill towards indigenous people when they formally recognised, with an overwhelming endorsement of the referendum proposals, the need for a national policy addressing indigenous issues. It seems plausible, then, that a substantial number of indigenous people were choosing not to identify in the official statistical collections before 1967. Since these missing generations will themselves have had progeny not identified as indigenous, there may be a considerable potential population who may not have identified as indigenous in the 1960s or even the 1970s (Taylor 2002b). Note that the low growth rates between the 1976 and 1981 censuses probably reflect the idiosyncrasies of those censuses (see Choi \& Gray 1985).

Similar observations of low growth rates in the indigenous population can be made for the US in the first half of the twentieth century. This also resulted in a 'pent-up' population pressure from a potential indigenous population with the numbers of American Indians increasing dramatically after 1950 (see Ross 2002).

While the 'error of closure' has only been estimated for the last few censuses, it appears to be generally positive and somewhat variable. Using the balancing equation, the error of closure for Australia during the 199196 period is calculated as 44,356 persons, or 12.6 per cent of the total indigenous count in 1996 (Ross 1999). In comparison, the error of closure for the American Indian population, was 9.2 per cent for the intercensal period, 1980-90 (Harris 1994), and 25.2 per cent for the 197080 period (Passell \& Berman 1986). 
Table 1

Indigenous Census Counts, Australia: 1901-2001

\begin{tabular}{|c|c|c|c|}
\hline $\begin{array}{c}\text { Census } \\
\text { Year }\end{array}$ & Count* & $\begin{array}{c}\text { Intercensal } \\
\text { Decade }\end{array}$ & $\begin{array}{c}\text { Annual } \\
\text { Growth Rate } \\
(\%)\end{array}$ \\
\hline 1901 & 93,333 & 1901-1911 & -1.0 \\
\hline 1911 & 84,527 & 1911-1921 & -1.6 \\
\hline 1921 & 71,836 & $1921-1933$ & 1.0 \\
\hline 1933 & 80,721 & $1933-1947$ & -0.4 \\
\hline 1947 & 75,965 & $1947-1954$ & -0.2 \\
\hline 1954 & 75,040 & 1954-1961 & 1.7 \\
\hline 1961 & 84,470 & $1961-1966$ & -1.0 \\
\hline 1966 & 80,207 & 1966-1977 & 7.6 \\
\hline 1971 & 115,953 & 1971-1976 & 6.8 \\
\hline 1976 & 160,915 & 1976-1981 & -0.1 \\
\hline 1981 & 159,897 & 1981-1986 & 7.3 \\
\hline 1986 & 227,593 & 1986-1991 & 3.1 \\
\hline 1991 & 265,371 & 1991-1996 & 5.9 \\
\hline 1996 & 352,970 & $1996-2001$ & 3.0 \\
\hline 2001 & 410,003 & & \\
\hline
\end{tabular}

* Note that prior to 1967 , Section 12 of the Australia Constitution did not allow a full enumeration of the indigenous population counts. Hence, the earlier counts were calculated on a different basis to the post-1967 estimates.

Source: Ross (1999: 10). Note that the 2001 estimates are based on Kinfu and Taylor (2005) and authors' calculations. 
Boyd H. Hunter and Mardi H. Dungey

The largest proportional increases in recent Australian census counts, and associated errors of closure, were in the highly urbanised south-eastern states. These areas experienced European settlement earlier than other areas and their rates of intermarriage resulted in a larger pool of persons of mixed ancestry than in areas where European settlement was later. It is this mixed ancestry group for whom it is likely that identification as indigenous has changed over time (Ross 1999).

The primary force behind the unexplained component of the increase in indigenous population appears to be related to what has been termed by Passel and Berman as 'recruitment' or changes in self-identification (1986: 164). Ross (1999) claims that the changes in the transmission of indigenous identity from parents to children in mixed couple families is evidence that 'recruitment' into the indigenous population is not only possible but did occur between 1991 and 1996. Data on age structures in Ross (1999) and elsewhere (Gray 1997a; 1997b; Hunter 1998) suggest that such 'recruitment', if it occurred, must have taken place in adult age groups as well.

The proportion of indigenous population growth between 1991 and 1996 that could not be accounted for by demographic factors was just over half (51\%) of the overall intercensal increase (Ross 1999: 24). For the most recent inter-censal period, the ABS has estimated a reduction in this error of closure to 26 per cent (ABS 2002).

Kinfu and Taylor (2005) provide an alternative set of estimates for the 1996-2001 period by correcting for census edits and by applying adjusted estimates of births and deaths. They estimate that 69 per cent of the change in the census count of indigenous Australians can be explained in terms of natural increase. The unexplained component, which amounts to 19,243 persons, accounts for 31 per cent of the intercensal population change and represents about 4.7 per cent of the total indigenous count in 2001. This improved estimate of the error of closure is still substantially lower than that observed for the 1991-96 period.

Gray and Tesfaghiorghis (1993) reported that the unexplained component of growth in the indigenous population was also relatively small for the 1986-91 period. That is, there is some evidence that the error of closure for the indigenous population varies between successive censuses. As noted earlier, a substantial number of people may have hidden their identity before 1967, and the progeny of such people may reveal their heritage in an uneven manner. Such 'revelation' may in turn be influenced by the political climate and the extent to which other relatives openly identify as indigenous.

One method for estimating the potential indigenous population is the DSE, sometimes referred to as 'dual survey estimators' or 'dual record systems'. The basic approach is to estimate the number of people missing from any particular enumeration using a follow-up survey (Marks, Seltzer \& Krtoki 
1974). Such a survey is undertaken after major censuses in most developed countries; in Australia it is known as the Post-Enumeration Survey (PES). ${ }^{1}$

Rather than provide another estimate of the error of closure, this paper estimates the total indigenous population using two alternative methods. The first method put forward is the DSE method where the number of indigenous people who fail to identify as such in the census are estimated using a statistical model of matched records in the PES. This methodology can be used to construct confidence intervals on the total indigenous population. The second method is the undercount directly calculated by the statistical agency, the ABS. In Australia this results in a figure for the total population, which is given as the recorded population plus an adjustment based on administrative follow-up of individual records in the PES (e.g., ABS 1997). This also allows us to place a confidence band around an estimate of the total indigenous population. The two estimates of total population are alternative and complementary. In one case, uncertainty is used to fill in the missing group, in the other case, the official undercount is being used to fill in the missing group. The two methodologies use the available information in different ways to obtain the final population estimates.

\section{The DSE Methodology}

The simplest DSE is a two-sample model. The first sample identifies certain individuals who are returned to the population after the survey is complete, while the second sample provides an independent measure of the population. Using the numbers of individuals in both samples and the numbers identified in just one sample, it is possible to estimate the number not captured in either sample, thus providing an estimate of the total population size. The assumptions required for such estimate to be valid are that:

1. There is no change to the population during the investigation (i.e. the population is closed);

2. Individuals can be matched from one sample to the next;

3. The chance of being in each sample is uncorrelated for each individual ; and

4. The two samples are independent.

The application of these methods to the study of epidemiological problems came relatively late in this history, and thus has been able to draw on advances in the other areas as well as in statistical methods more broadly. Sekar and Deming were the first to adapt the method for human populations when they used the method to estimate birth and death rates, 
Boyd H. Hunter and Mardi H. Dungey

and the extent of their registration in 1949, with hospital data from India. There is also a substantial literature going back to the 1940 s, dealing with the application of the two-sample method to census data (Fienberg 1992). By taking another sample in addition to the census, the method can be used for estimating undercount by the census. The history of the application of DSEs to the US census are described by Hogan (1993).

In terms of the validity of assumptions for estimating the potential numbers of indigenous Australians, it is necessary to confine our attention to closed populations. Even populations with high mobility, such as people in remote indigenous communities, may be considered 'closed' so long as the PES or follow-up survey takes place shortly after the initial survey or census (Paradies et al. 2000).

With respect to assumption (2), matching will depend on the quality of the census records and the uniqueness of respondents' names. The ABS (1997: 7) gives a detailed assurance that all due care is taken to match and search the respective census and PES responses. ${ }^{2}$ In the PES, respondents are asked a number of questions about where they live, and addresses where they might have been counted in the census, including:

- if they thought they were counted on a census form (and if so where); and

- $\quad$ where they were on census night (ABS 1997: 25).

Another of the assumptions required for DSEs to be valid is the homogeneity of the population (assumption 3 above). That is, all the members in the population should have the same chance of being sampled in the follow-up survey. However, this assumption could be violated if, for example, variations in socioeconomic status within the population mean that members of the population may actually differ considerably in the chance of being ascertainedby a particular source. Such heterogeneity, within the population, may cause problems in DSE. While data that relies on voluntary reporting should be used cautiously, it should be noted that it is compulsory to answer ABS surveys under the Australian Census Act 1905. Also note that survey weights are constructed to allow ABS to equate probability of inclusion in a sample - this reinforces our confidence in the validity of assumption 3 in the current context.

The question of independence is discussed by Sekar and Deming (1949) in some detail (also see Marks, Seltzer \& Krtoki 1974). While the assumption of independence may not be valid in many circumstances, the ABS applies procedures to preserve the independence of the census and PES. For example, given that some people may have been prompted to return their census forms by the arrival of the PES preliminary letter or the interviewer 
(ABS 1997: 8), the follow-up survey is held three weeks after the official date of the census to ensure that all forms have been completed and returned. ${ }^{3}$

A further issue, which can cause problems for the DSE methodology, is that of coverage. If there are individuals who are not sampled in both samples, this results in potential upwards bias of the estimates (Shyrock and Siegel and Associates 1976). For Census data, this source of error should be relatively small. However, there are clearly some people who are missed from the Census, and hence the PES, and these people may be more likely to be indigenous than non-indigenous. To the extent this is true the standard errors constructed using DSE overstate the accuracy of the estimate. However, in this case this bias is anticipated to be small. ${ }^{4}$

\section{Responses to the Questions on Indigenous Status for Australian PES, 1991-2001}

The information from DSEs is based on observed variation between an individual's response to the indigenous status question on a census and follow-up survey. This section documents the responses to the indigenous question between 1991 and 2001 censuses.

Hunter (1998) presents the 1991 and 1996 data required to estimate the potential indigenous population. In 1991, only 1.4 per cent of those who provided a valid response for the question on indigenous status indicated they were indigenous in both the survey and the Census. Equal numbers of respondents $(0.3 \%)$ changed from indigenous to Non-indigenous between census and PES, and vice versa.

For the 1996 data, there was less variation between the census and PES. While there was a slight increase in the percentage who indicate that they were indigenous in both $(1.5 \%)$, there was a slight reduction in the number who changed from being non-indigenous in the census to indigenous in the PES $(0.1 \%)$.

One particularly interesting feature is that the percentage of people who identify as non-indigenous in both the PES and the census is identical in both 1991 and 1996 (98.1\%). Inverting this, the percentages of people who identify as indigenous in some way were identical in both of these years. Thus, the proportion and hence number of people who identify as indigenous appears to be more stable than the prima facie evidence indicates. Arguably, the propensity to identify as indigenous also became more reliable, with fewer people changing their response to the indigenous status question. However, while there was some minor variation in changes in response, the results are broadly similar between 1991 and 1996.

ABS (2002) showed that the 2001 Census saw a small, but potentially important, fall in the proportion of people who identified as non- 
Boyd H. Hunter and Mardi H. Dungey

indigenous in both the census and the PES (from 98.1\% to 97.3\%). The proportion who changed identification from non-indigenous to indigenous between the 2001 Census and PES (and vice versa) was 0.2 per cent (and $0.4 \%$ ). The reliability of the 2001 estimates is likely to have been diminished by the reduction in size of the PES survey in that year (by around 20,000 from the previous PES). However, the fall in nonindigenous identification is consistent with there being some 'recruitment' into the potential indigenous population. Given the prolonged period of relatively low population growth, it would not be surprising if this were the case. Other possible explanations lie in the higher fertility rates in the indigenous population (Kinfu \& Taylor 2005), or changes in the coverage of the respective censuses.

A comparison of the 1991 estimates with those for 1996 and 2001 provides the interesting result that people who identify as indigenous in the Census only is a larger proportion that those who identify as indigenous in only the PES. This may be at least in part due to the different modes of collection, the Census is a self-administered form and the PES a face-to-face interview. The McNemar test of marginal homogeneity considers the hypothesis that there is no correlation between identifying as indigenous and the form of the data collection. ${ }^{5}$ The McNemar test statistics for 1991, 1996 and 2001 are $0.9,65.0$ and 34.0 respectively. The 1991 results accept the null hypothesis of marginal homogeneity, while the 1996 and 2001 results do not. This result is a particularly interesting avenue for future work as we can find no evidence of any substantive break in the data collection methodology between these different surveys.

\section{DSE Estimates of the Indigenous Population}

The mathematical formula provided in Appendix A can be used to derive new population estimates for indigenous Australians, under the assumption that the sampling is done from a superpopulation (see Graubard and Korn (2002) for a recent discussion of the biases which may result if this assumption is violated). However, the PES does not cover the whole of Australia, and it is therefore necessary to make some distributional assumptions about the indigenous population in areas outside the scope of the PES.

The PES is not conducted in remote areas or in discrete indigenous communities. Because of this it is not possible to analyse directly the changes in identification of remote residents. However, only 0.5 per cent of the population enumerated on the remote area Special indigenous Forms (SIFs) in 1991 were non-indigenous (Evans, Kahles \& Bate 1993: 25). Therefore, the scope for a 'DSE-style' undercount of the indigenous population is constrained in the sense there are relatively few nonindigenous people to change their response to the indigenous status question. Given that remote areas had a very low 'error of closure' (Ross 
1999), it is reasonable to assume that indigenous identification in the respective census counts can be taken as being accurate.

The population in these remote areas was calculated using the 1991 and 1996 counts in Collection Districts that did not use SIFs. In the absence of any better information, the rate of indigenous identification in non-PES areas for the census was taken as given. This approach was adopted to account for the differential rates of indigenous identification in PES and non-PES areas. Tests of the sensitivity of the outcomes to this assumption are also undertaken in what follows.

Table 2 provides two estimates for 2001 because the ABS has not yet released any data on the indigenous census counts in non-PES areas to date. Consequently the 2001 estimates are bounded by two extreme assumptions: firstly, that the population in non-PES areas did not change and, secondly, that all indigenous population growth in remote areas occurred in non-PES areas. Note that there is little difference in the DSE estimates for 2001, irrespective of the assumption used.

When using this method, the estimate of the complete indigenous population increases from 304,751 to 372,983 between 1991 and 1996 . The 2001 estimates are both around 446,000. The 95 per cent confidence intervals of the estimates are a band of between 3,500 and 5,000 around these estimates.

In addition to the point estimates and the 95 per cent confidence intervals, Table 2 also presents the growth rate of the potential population, which is more constant than the gross rates of growth reported in Table 1. That is, the potential indigenous population grew by around 20 per cent in the two most recent intercensal periods. The growth rate declined slightly in the last intercensal period, probably because of the recent decline in indigenous fertility rates (Kinfu \& Taylor 2005).

As indicated above, this methodology treats the indigenous population of non-PES areas as being fixed (i.e. having a standard error of zero). This assumption can be relaxed, but the sensitivity analysis is not reported in any detail in order to simplify exposition. Suffice to say that the confidence interval would only increase by between 1,000 and 2,000 if the indigenous population were scaled to the total population counts rather than only to the counts for PES areas (and then adding the indigenous population for non-PES areas). That is, confidence intervals only increase marginally if the indigenous population estimates are assumed to have the same variance in PES and non-PES areas.

A side-effect of scaling the PES results to the total Australian population is that it imposes an indigenous undercount result in non-PES areas, and hence increases the estimate by about 17,000. In 1996, this increases the size of the estimate to a little over the experimental estimate in ABS (1998) of 386,000 people. This effect is undesirable if one accepts the argument that there is a limited scope for an undercount in non-PES areas. However, since it is not possible to discount an undercount in such areas, 
one approach might be to extend the confidence intervals to take in this possibility. While this is somewhat arbitrary, it should be noted that the DSE estimates of the confidence intervals are exceptionally tight, probably as a result of both the treatment of non-PES areas and the simplifying assumption of normality (of the statistical distribution) that has to be made when using grouped data from the PES. We are particularly mindful of the possibility of providing a misleading sense of precision in these DSE estimates, and will return to these points in the concluding discussion.

\section{Table 2}

DSE Estimates of Potential Indigenous Population Australia: 1991-2001 ${ }^{\mathrm{a}}$

\begin{tabular}{lcccc}
\hline & 1991 & 1996 & $2001^{\mathbf{a}}$ & $2001^{\mathbf{b}}$ \\
\hline $\begin{array}{l}\text { Indigenous } \\
\text { Population }\end{array}$ & 304,751 & 372,983 & 445,714 & 446,902 \\
& & & \\
95\% Confidence Intervals (based on $\mathrm{N} \pm 1.96^{*}$ & standard errors) \\
Upper & 307,442 & 374,703 & 448,377 & 449,654 \\
Lower & 302,060 & 371,262 & 443,051 & 444,150 \\
Intercensal & \multicolumn{5}{c}{$1996-2001^{\mathrm{a}}$} & $1996-2001^{\mathrm{b}}$ \\
Growth & \multicolumn{5}{c}{$19.5 \%$} & $19.8 \%$ \\
& & $22.4 \%$ & & \\
\hline
\end{tabular}

${ }^{a}$ The act of distributing the not stated category for the question on indigenous status makes virtually no difference to the estimates reported in this table.

Having identified several weaknesses in the DSE estimates of the indigenous population, we now benchmark them against alternative estimates. The most obvious alternative is the standard ABS undercount estimates of the indigenous population that permit the analyst to construct confidence intervals around the population. 


\section{Estimates Based on the ABS Undercount Methodology}

The ABS undercount refers to the number of people missed in the census for one of the following reasons: they were difficult to contact (e.g. travelling); they mistakenly thought they were counted elsewhere; there was insufficient space on the census form; the person completing the census form thought babies, the elderly and visitors should not be included; respondents were reluctant to participate (e.g. confidentiality concerns); or the dwelling was mistakenly classified as unoccupied. Sanders (2002) identified that certain census collectors simply overlooked the existence of a number of indigenous people in 'town camps'. An 'overcount' refers to where people are counted too many times (e.g. duplicates). The net undercount is the difference between gross undercount and overcount.

One relatively intuitive means of estimating variability of the indigenous population is to use the standard errors on the census undercount (ABS 1997). The ABS define the undercount rate as:

final undercount rate $=\frac{\text { final population estimate }- \text { census count }}{\text { final population estimate }}$

where the final population estimate refers to the estimate for the group under consideration, eg a regional or ethnic sub-group. We have data available on the final population estimate and the initial census count. However, the ABS also makes a number of adjustments to this data to account for demographic irregularities and inconsistencies with alternative, often administrative, data sources. Hence the undercount rate calculated from the published ABS data on final population and census data does not produce the official ABS undercount rates. Note that the final population estimate is not the same figure as given in the Estimated Residential Population, which gives breakdowns of adjustments and includes information from other sources (compare Tables 7 and 11 in ABS 1998).

Appendix B shows how the undercount for the respective censuses can be used in conjunction with the census counts from Table 1 to produce estimates of the indigenous population. For the 1996 Census we have an indigenous person undercount rate of 7.1 per cent with a standard error of 1.04 per cent. For 1996 data, the population is estimated using this technique to be around 379,950 . Given the emphasis of this paper on the reliability of estimates, it is important to note that we can be 95 per cent confident that the 'true' indigenous population lies somewhere between 371,800 and 388,500 . That is, there is a band of approximately: 8,000 (or about $2.1 \%$ of the total indigenous population) on either side of the point estimate.The 1991 undercount for the indigenous population was 3.6 per cent (Evans, Kahles \& Bate 1993). The standard error for the undercount is 
Boyd H. Hunter and Mardi H. Dungey

remarkably high, at 7.2 per cent. Given the unadjusted population count reported in Table 1, the above technique gives a 95 per cent confidence interval that the true population lies between 240,155 and 322,443. Part of this range is less than the count in Table 1, implying that there may have been an overcount. However, this is more likely to reflect sampling error in the PES. In view of this large confidence interval, it is not surprising that the probable array of DSE estimates for 1991 lies in this range.

Note that the results reported in this section use the initial census counts to estimate the confidence intervals for the indigenous population as the DSE estimates in the previous section are also scaled by these counts. This assumption also avoids any circularity in the logic between the conventional demographic adjustments and the use of an adjusted census count. For the purposes of this paper, the differences between using the initial or adjusted census data are not important because the following analysis are produced solely for the purposes of benchmarking the DSE estimates and associated standard errors. The DSE estimates for 1996 are almost entirely within the confidence interval estimated using undercount data. The relatively small confidence interval might be expected given that DSEs do not take into account other (demographic) information included in the official estimates. However, it should also be possible for the ABS to make similar augmentations to the DSE estimates that facilitate more direct comparisons with other estimates of the indigenous population. The important thing is to get a sense of the variability of population estimates so policy makers can identify the potential sensitivity of the assumptions underlying their policy prescriptions.

\section{Policy and Methodological Implications}

Accurate indigenous population estimates are essential for ensuring policy is effective and in estimating service delivery requirements. The DSE estimates of the indigenous Australian population are consistent with the official estimate provided by the ABS. This paper attempts to highlight the importance of assessing the reliability of indigenous population estimates through providing standard errors and confidence intervals. Notwithstanding the DSE's apparent reliability, it is important to recognise their limitations. In addition to ignoring other demographic information, no attempt has been made to take into account sampling error and survey design effects arising from the PES. Only the ABS is in a position to provide such information. They could do this by either using a DSE (and related standard errors) to estimate the indigenous population themselves, or by being more transparent in their undercount publications in ways that permit an estimate of sampling error and design effects in the PES. Not only could the ABS develop an alternative set of population estimates for indigenous Australians, but this may also be a worthwhile exercise for many sub-populations of interest to policy makers (e.g. people from nonEnglish speaking backgrounds). 
By providing more information about the distribution of estimates from the PES, the ABS will facilitate sensitivity analysis of the assumption of normality in DSE, which we were forced to impose. For example, given the small number identifying as indigenous in the PES, the distribution of the estimates of people who change their response to the indigenous status question is probably closer to a Poisson distribution than the Normal distribution. The distinct properties of the Poisson distribution (such as asymmetry) mean that appropriate standard errors will not be consistent with those derived assuming normality. One remedy for this situation is to simulate the standard errors and confidence intervals using the bootstrap method (see MacKinnon 2002). Unfortunately, confidence intervals cannot be bootstrapped, unless one has access to unit record data for the PES. For this reason, the ABS should be encouraged to estimate DSEs of the indigenous population.

It may not be possible to get away from reliance on the standard techniques, due to the ongoing problems in matching indigenous individuals in remote areas (Martin et al. 2002). It would also be extremely difficult to ensure that all the census forms were collected in remote areas by the time of the PES. Increasing the time between the census and the PES does not solve this problem as it has the drawback that it decreases the prospect that the population is closed.

In any case, even if there is a large sample in the follow-up survey, this does not guarantee reliable estimates. If estimating local population level is intractable, then one could question the worth of releasing indigenous data for small areas such as indigenous locations (ABS 2002). The problem is that there is no sense of the variability of such estimates because they are based simply on actual counts. Note that the reported population distribution across local areas may be misleading and biased if the undercount rate differs in the various areas. While augmenting the national PES sample is unlikely to be the answer, the ABS should consider conducting a small scale DSE in selected remote areas, in order to explore the differences in the undercount rates between remote and other areas. This would help in assessing the magnitude of the biases involved. There are surprisingly few studies that examine the validity of the census counts in remote indigenous communities (Taylor \& Bell 2002).

While the use of DSE (and other demographic) adjustment to the population estimates tends to be less biased than unadjusted census counts the estimates are more unreliable because they are based on survey data (Zaslavsky 1993). Zaslavsky argues that the incorporation of a third piece of independent evidence will reduce both the variance and the bias. ${ }^{6}$

The central theme of this paper is that policy makers need to take into account the fact that population statistics for minority groups from the census are merely estimates. This can have important implications for policy outcomes. For example in the Australian context the distribution of fiscal funding across States is dependent on the regional indigenous population. More broadly, regional population estimates influence political 
Boyd H. Hunter and Mardi H. Dungey

representation in systems where electoral boundaries and appropriate numbers of political representatives are determined by population.

For example, the Australian Electoral Commission (AEC) reduced the number of federal members of parliament for the Northern Territory in 2003 based on an ABS revision of the Territory's population, which fell under the population threshold by 295 people (AEC press release, 20 February 2003). The initial population estimates for the Northern Territory were based on PES collections adjusted using estimates for the entire population, without adjustment for remote area populations where the PES is not conducted. While it is not clear what bias is introduced by this assumption, the ABS's operational assumption that the structure of underenumeration is the same in remote and non-remote areas will detract from the reliability of revised estimates. This means that the revised population estimate is even less likely to be significantly different from the threshold set by the AEC. ${ }^{7}$ Clearly, policy makers need to be aware that population estimates are not entirely accurate and could be subject to revision if more information were collected. A state of 'closure' will not be attained until the issues of potential bias and reliability of estimates are fully addressed in both remote and other areas.

The title of this paper is intended to convey a sense of irony in that while 'closure' is a worthy aspiration, it is not a goal that is not likely to attained easily because of the difficulties in measuring the reliability of population estimates in the presence of endogenous ethnicity. This is not necessarily a novel point as Guimond (1999) highlighted the role of ethnic mobility in making for a low level of temporal reliability in the time series for Aboriginal people in Canada. Notwithstanding such difficulties, it is salutary to remind policy-makers from time-to-time that population estimates are just that, estimates based on various methodologies which have their respective strengths and weaknesses.

\section{End Notes:}

1. The Australian PES is an interviewer-based survey conducted three weeks after census night which allows comparison of the responses in the census and the PES to identify whether they have changed. Here we use a matched sample of those who responded to both the Census and the PES. It is also possible that the PES may pick up some uncounted population from the Census, both samples are drawn from the population as a whole. Information is collected to determine whether persons have been missed or double counted in the census and whether dwellings were missed. The PES collects personal information on indigenous origin, age, sex, marital status and birthplace. Note that there are several differences between the census and PES collections. For example, the census question on indigenous 
status is based on self-identification whereas the PES involves an interviewer. In addition there were slight differences in the wording of the question. More importantly, the PES question is asked of the entire household whereas the census is asked of each person individually.

2. In the event that the PES results in clustering in the data, this will result in biased standard errors. However, it is not possible to determine the extent (if any) of clustering from publicly available data.

3. It should be noted that the PES is not conducted in all areas. In remote communities, a 'rolling count' is applied because of the complexity and time-consuming nature of the census collection. Hence, it is not possible to conduct the PES on the same basis as is done in other areas.

4. A good discussion on the debate over the PES, and its application to estimating the 'true' populations of self-identified groups, is given in the papers contained in Vol. 88 of the Journal of the American Statistical Society, particularly Hogan (1993).

5. Using the terminology of Appendix A, the McNemar test is constructed as $(\mathrm{x} 12-\mathrm{x} 21)^{\wedge} /(\mathrm{x} 12+\mathrm{x} 21)$ and is distributed as a $\chi^{2}(1)$. An alternative specification is $(|\mathrm{x} 12-\mathrm{x} 21|-1)^{\wedge} /(\mathrm{x} 12+\mathrm{x} 21)$ also distributed as a $\chi^{2}(1)$. These alternates make no difference to the result in this case.

6. For example, conditioning on age distribution and male/female ratios can improve DSE-based estimates.

7. Note that it is entirely possible that the estimates would be lower if the ABS benchmarked its undercount assumptions for remote areas.

\section{References:}

ABS. 1997. Information Paper: Census of Population and Housing: Data Quality-Undercount, cat. no. 2940.0, Canberra: ABS.

ABS. 1998. Experimental Estimates of the Aboriginal and Torres Strait Islander Population, ABS cat. no. 3230.0, Canberra: ABS.

ABS. 2002. Population distribution, Aboriginal and Torres Strait Islander Australians 2001, cat. no. 4705.0, Canberra: ABS.

Chao, A. 1989. "Estimating population size for sparse data in capturerecapture experiments", Biometrics, 45: 427-38. 
Boyd H. Hunter and Mardi H. Dungey

Choi, C. and A. Gray 1985. "An Evaluation of Census Counts of the Aboriginal Population, 1971, 1976 and 1981”, Occasional Paper No. 2, Canberra: ABS

Evans, J., D. Kahles and C. Bate. 1993. “1991 Census Data Quality: Aboriginal and Torres Strait Islander Counts", Census Working Paper 93/6, Canberra: ABS.

Fienberg, S.E. 1992. "Bibliography on capture-recapture modeling with application to census undercount adjustment", Survey Methodology, 18 (1): 143-54.

Gardiner, G. and E.A. Bourke. 2000. "Indigenous populations, 'mixed' discourses and identities", People and Place, 8 (2): 43-52.

Graubard, B.I. and E.L. Korn. 2002. "Inference for Superpopulation parameters using sample surveys", Statistical Science,17 (1),73-96.

Gray, A. 1997a. "The explosion of aboriginality: components of Indigenous population growth 1991-96”, CAEPR Discussion Paper No. 142, Canberra: CAEPR, ANU.

Gray, A. 1997b. "Growth of the Aboriginal and Torres Strait Islander population, 1991-2001 and beyond", CAEPR Discussion Paper No. 150, Canberra: CAEPR, ANU.

Gray, A. and H. Tesfaghiorghis. 1993. "Aboriginal population prospects", Journal of the Australian Population Association, 10 (2): 81-101.

Greene, W.H. 2000. Econometric Analysis, New Jersey: Prentice Hall.

Guimond, É. 1999. Ethnic mobility and the demographic growth of Canada's aboriginal populations from 1986 to 1996, Ottawa: cat. no. 91-209-XPE, Statistics Canada.

Harris, D. 1994. “The 1990 Census Count of American Indians: What Do the Numbers Really Mean?" Social Science Quarterly, 75 (3): 580-93.

Hogan, H. 1993. "The 1990 post-enumeration survey: operations and results", Journal of the American Statistical Association, 88: 1047-60.

Hunter, B.H. 1998. "Assessing the validity of intercensal comparisons of Indigenous Australians, 1986-96”, Journal of the Australian Population Association, 15 (1): 51-67.

Kinfu, Y. and J. Taylor. 2005. "On the components of Indigenous population change”, Australian Geographer, 36 (2): 233-55. 
Creating a Sense of 'CLOSURE',: Providing Confidence Intervals on some Recent Estimates of Indigenous Populations

MacKinnon, J. 2002. "Bootstrap inference in econometrics", Canadian Journal of Economics, 35 (4): 51-67.

Marks, E.S., W. Seltzer and K.J. Krtoki. 1974. Population Growth Estimates: A Handbook of Vital Statistics Measurement, New York: The Population Council.

Martin, D.F., F. Morphy, W.G. Sanders and J. Taylor. 2002. Making Sense of the Census: Observations of the 2001 Enumeration in Remote Aboriginal Australia, Research Monograph No. 22, Canberra: CAEPR, ANU.

Paradies, Y., S. Huppatz, J. Warnsey and T. Barnes. 2000. Population and globalisation: Australia in the 21 st century, Paper presented at the 10th Biennial Conference of the Australian Population Association, Melbourne, November.

Passel, J.S. 1976. "Provisional evaluation of the 1970 census count of American Indians", Demography, 13: 397-409.

Passel, J.S. 1996. "The growing American Indian population, 1969-1990: beyond demography". in G. D. Sandefur, R. R. Rindfuss and B. Cohen (eds) Changing Numbers, Changing Needs: American Indian Demography and Public Health, Washington D.C.: National Academy Press.

Passell, J.S. and P.A. Berman 1986. "Quality of 1980 Census Data for American Indians”, Social Biology, 33 (3-4): 163-82.

Ross, K. 1999. Occasional Paper: Population Issues, Indigenous Australians, cat. no. 4708.0, Canberra: ABS.

Ross, K. 2002. "Recent trends in the demography of the indigenous populations of Australia, New Zealand, Canada and the United States of America". in G. Biscoe and L. Smith (eds) The Aboriginal Population Revisited: 70000 Years to the Present, Canberra: Aboriginal History Monograph 10, ANU.

Sandefur, G.D., R.R. Rindfuss and B. Cohen. 1996. Changing Numbers, Changing Needs: American Indian Demography and Public Health, Washington D.C.: National Academy Press.

Sekar, C. and E.W. Deming. 1949. "On a method of estimating birth and death rates and extent of registration", Journal of the American Statistical Association, 44 (1): 101-15. 
Boyd H. Hunter and Mardi H. Dungey

Shyrock, H.S., J.S. Siegel and Associates. 1976. The Methods and Materials of Demography, London: Academic Press.

Snipp, M.C. 1997. "Some observations about racial boundaries and the experiences of American Indians", Ethnic and Racial Studies, 20 (4): $667-89$.

Taylor, J. 1997a. "Changing numbers, changing needs? A preliminary assessment of indigenous population growth 1991-1996", CAEPR Discussion Paper No. 143, Canberra: CAEPR, ANU.

Taylor, J. 1997b. "The contemporary demography of indigenous Australians", Journal of the Australian Population Association, 14 (1): $77-114$.

Taylor, J. 2002a. "The context of observation". in D. F. Martin, F. Morphy, W. G. Sanders and J. Taylor (eds) Making Sense of the Census: Observations of the 2001 Enumeration in Remote Aboriginal Australia, Research Monograph No. 22/2002, Canberra: CAEPR, ANU.

Taylor, J. 2002b. "Indigenous enumeration in the late twentieth century: Emerging issues for population analysis". in G. Briscoe and L. Smith (eds) The Aboriginal Population Revisited: 70000 Years to the Present, Canberra: Aboriginal History Monograph 10, ANU.

Taylor, J. and M. Bell. 2002. "Benchmarking ABS population estimates for Queensland Aboriginal and Torres Strait Islander communities", Discussion Paper 1/2002, Brisbane: QCPR, University of Queensland.

Wolter, K. 1987. "Census Undercount and the Quality of Geographic Population Distributions: A Comment", Journal of the American Statistical Association, 80 (400): 978-80.

Zaslavsky, A.M. 1993. “Combining Census, dual-system, and evaluation study data to estimate population shares", Journal of the American Statistical Association, 88 (423): 1092-105. 


\section{Appendix A. Applying the DSE Method}

The key to this method is an ability to match individual records, on some different criteria to the one of interest, and then check the observation of interest for consistency. In a two-outcome situation, such as a yes/no question, four potential outcomes occur, as illustrated in Table A1. First, the record can be 'yes' on both the initial and second surveys, designated by the cell $\mathrm{x}_{11}$. Second, the record can be 'yes' on the first and 'no' on the second, designated by the cell $\mathrm{x}_{12}$. Third, the record can be 'no' on the first and 'yes' on the second, denoted by cell $x_{21}$, and finally the record can be 'no' on both surveys, given by $x_{22}$. This method cannot, of course, pick up information that has been incorrectly recorded on both surveys (e.g. respondents answering 'yes' on both surveys when the true observation was 'no').

\section{Table A1}

A Two Outcome Example of DSE Methodology

\begin{tabular}{cccc}
\hline Response B & \multicolumn{3}{c}{ Response A } \\
Yes & $\mathrm{x}_{11}$ & $\mathrm{x}_{12}$ & Total \\
No & $\mathrm{X}_{21}$ & $\mathrm{X}_{22}$ & $\mathrm{X}_{11}+\mathrm{x}_{12}$ \\
Total & $\mathrm{X}_{11}+\mathrm{x}_{21}$ & $\mathrm{x}_{12}+\mathrm{x}_{22}$ & $\mathrm{X}_{21}+\mathrm{x}_{22}+\mathrm{x}_{22}+\mathrm{x}_{12}+\mathrm{x}_{22}$ \\
\hline
\end{tabular}

DSEs rely on there being a difference in response between one collection and the next. Using the Sekar-Deming (1949) formula, the revised population estimate is:

$$
\hat{N}=\mathrm{x}_{11}+\mathrm{x}_{12}+\mathrm{x}_{21}+\mathrm{x}_{12} \mathrm{x}_{21} / \mathrm{x}_{11}
$$

If Table A1 refers to the response to a question about indigenous status, then only $\mathrm{x}_{22}$ people always deny they are indigenous. However, some of the $\mathrm{x}_{22}$ people may also admit to being indigenous in other circumstances. The 4 th term on the right-hand side of equation $1 \mathrm{~A}$ is the number expected 
to identify as indigenous at least once if surveys are 'independent' (in statistical terms). ${ }^{1}$

The variance of $N$ can be estimated using the standard binomial approach as

$$
\operatorname{Var}(\hat{N})=\sqrt{ }\left(\hat{N} \hat{\mathrm{q}}_{1} \hat{\mathrm{q}}_{2} / \hat{\mathrm{p}}_{1} \hat{\mathrm{p}}_{2}\right)
$$

where

$$
\begin{aligned}
& \hat{p}_{1}=x_{11} /\left(x_{11}+x_{21}\right) \\
& \hat{p}_{2}=x_{11} /\left(x_{11}+x_{12}\right) \\
& \hat{p}_{1}+\hat{q}_{1}=\hat{p}_{1}+\hat{q}_{2}=1
\end{aligned}
$$

That is, $\hat{p}_{1}$ refers to the proportion of people who answered 'yes' in both surveys compared to the total number of people who answered 'yes' in survey A. Similarly $\hat{p}_{2}$ refers to the proportion of people who consistently answered 'yes' in both surveys compared to those who answered 'yes' in survey B. The proportions, $\hat{q}_{1}$ and $\hat{q}_{2}$ reflect the alternative scenario in each case.

In earlier work, a natural approach to the construction of confidence intervals was to assume that $\hat{N}$ was asymptotically normal and use $\hat{N} \pm$ 1.96 standard errors. Unfortunately the distribution of $N$ is often skewed in practice and the above interval can give misleading results. To get around this one might try and find a suitable transformation that would make the distribution look more like a normal random variable (Chao 1989). Another approach is to use the bootstrap method for numerically estimating an appropriate confidence interval (Greene 2000). To do this requires knowledge of the sample distribution, which could be obtained from the underlying unit-record data for the Census and PES. For reasons of confidentiality this is not available to outside researchers, but this could be undertaken by the collecting statistical agency, although it would be a nontrivial exercise. 
Creating a Sense of 'CLOSURE',: Providing Confidence Intervals on some Recent Estimates of Indigenous Populations

\section{Appendix B}

\section{Constructing Confidence Intervals on Population Estimates using ABS Undercounts}

The results reported in the text use the initial census counts to estimate confidence intervals for the indigenous population, since the DSE estimates are also scaled by these counts. Another reason for this procedure is to avoid any duplication or circularity in the logic between the ABS's demographic adjustments and the use of an adjusted census count. For the purposes of this paper, the difference between using the initial or adjusted census is not important because the following calculations are produced solely for the purposes of benchmarking the DSE estimates and associated standard errors.

$$
\begin{array}{ll}
\text { If denote } & \text { final undercount rate }=\mathrm{r} \\
& \text { undercount population estimate }=\mathrm{y} \\
& \text { census count }=\mathrm{x},
\end{array}
$$

then $\quad \mathrm{r}=1-\mathrm{x} / \mathrm{y}$,

which can be re-expressed:

$$
\mathrm{x}=(1-\mathrm{r})^{*} \mathrm{y} \text { and } \mathrm{y}=\mathrm{x} /(1-\mathrm{r})
$$

For the 1996 Census we have an indigenous undercount rate of 7.1 per cent with a standard error of 1.04 per cent. The undercount population estimate and census counts for 1996 are 379,950 and 352,970. The 95 per cent confidence intervals for the undercount is $1.96 * 1.04 \pm 7.1$, giving an upper bound of 9.14 per cent and a lower bound of 5.06 per cent. Using our estimate of $\mathrm{x}$ above we calculate $\mathrm{y}_{\mathrm{u}}$ and $\mathrm{y}_{1}$ as:

$\mathrm{y}_{\mathrm{u}}=352,970 /(1-0.0914)=388,500$

$\mathrm{y}_{1}=352,970 /(1-0.0506)=371,800$ 